\title{
Intermediate Vascular Neoplasm
}

National Cancer Institute

\section{Source}

National Cancer Institute. Intermediate Vascular Neoplasm. NCI Thesaurus. Code C7334.

A vascular neoplasm with borderline malignant potential. 